\title{
O DIREITO NA TEORIA DE NIKLAS LUHMANN: OBSERVAÇÕES ACERCA DO “FECHAMENTO” AUTOPOIÉTICO DO SISTEMA JURÍDICO
}

\author{
Marcelo Oliveira de Moura ${ }^{1}$ \\ Thiago Ribeiro Rafagnin ${ }^{2}$
}

\begin{abstract}
Resumo
O presente artigo, resultante de uma revisão bibliográfica interdisciplinar, trata das características do sistema jurídico, conforme atribuídas por Niklas Luhmann, em sua construção teórica sistêmica. Nessa perspectiva, seu objeto de reflexão encontra-se nas (in)compreensões acerca do caráter autopoiético do Direito. Nesse ínterim, com foco nas percepções de fechamento estrutural e abertura cognitiva dos subsistemas sociais, buscou-se demonstrar como se dão as relações (comunicações) entre o Direito e os demais subsistemas da sociedade. Para tanto, o trabalho apresenta uma revisita biográfica e teórica, resgatando os elementos que permitem compreender adequadamente a teia epistemológica constituída pelo sociólogo alemão.
\end{abstract}

Palavras-chave: Niklas Luhmann; Sistema Jurídico; Autopoiese; Direito; Teoria Sistêmica; Epistemologia

\section{INTRODUÇÃO}

Os câmbios significativos na realidade social do último século têm provocado uma rediscussão sobre a capacidade da sociologia e do direito no que se refere à leitura dos fenômenos sócio-jurídicos. A sociedade, no entanto, apresenta-se cada vez mais complexa, colocando em xeque as respostas dadas a partir dos paradigmas tradicionais e seus recortes simplificadores. Ao buscar avanços em termos de complexidade, é elaborada a "Teoria dos Sistemas Sociais" de Niklas Luhmann, ofertando outro mapa epistemológico da realidade social, que pretende dar conta da compreensão da sociedade e todos os fenômenos que nela apresentam-se.

O caráter original da construção teórica de Luhmann, edificada a partir da ruptura com a teoria sociológica centrada no sujeito e na ação social, sua interdisciplinaridade e o vínculo com autores como Talcott Parsons (rotulado como conservador no âmbito das ciências sociais) têm gerado inúmeras críticas e preservado alguns preconceitos que obscurecem sua potencialidade de desvelamento de fenômenos importantes da realidade social contemporânea.

\footnotetext{
${ }^{1}$ Doutor em Direito (Unisinos). Professor do Programa de Pós-Graduação (Mestrado e Doutorado) em Política Social da Universidade Católica de Pelotas (UCPEL). Professor do Curso de Graduação em Direito da Universidade Católica de Pelotas (UCPEL).E-mail: mardmoura@hotmail.com

${ }^{2}$ Doutorando em Política Social na Universidade Católica de Pelotas (PPGPS-UCPel).E-mail: rafagnin40@hotmail.com
} 
Dentre os (pré)juízos resultantes de (in)compreensões apressadas, destaca-se o equivocado entendimento de "sistema" e de seu caráter autopoiético, um dos pontos fulcrais da teoria luhmanniana. A confusão entre a noção de fechamento do sistema e sua auto-referência faz imperar, em alguns círculos acadêmicos, uma errônea percepção de isolamento e independência dos sistemas em relação ao seu ambiente.

Especificamente relacionado com as feições do sistema jurídico, tal desentendimento acerca da noção de fechamento operacional do sistema e sua inerente abertura cognitiva, faz crer, inadequadamente, que o Direito é um sistema que se encontra absolutamente isolado da influência social, política, econômica etc., condenado à autolegitimação e a preservação das estruturas de dominação.

O presente artigo está inserido em um trabalho bibliográfico, cujo escopo principal é de apresentar uma análise sobre a ideia luhmanniana de autopoiesis e a noção de "fechamento do sistema do direito". Portanto, a investigação - sem a pretensão de esgotamento - traz em sua delimitação e precisão, uma aproximação da questão relativa às incompreensões relacionadas com o caráter operacionalmente fechado e cognitivamente aberto do sistema jurídico, colocando em segundo plano - como projeto a ser resgatado no futuro - um aprofundamento de outros aspectos da obra de Luhmann.

\section{NIKLAS LUHMANN E A TEORIA DOS SISTEMAS: CONTEXTUALIZANDO BIOGRÁFICA, HISTÓRICA E TEORICAMENTE}

Nessa parte do escrito, de caráter preliminar e introdutório, objetiva-se oferecer, numa síntese "apertada", os principais dados biográficos, bem como uma reflexão sobre a história do pensamento do autor alemão, com o escopo de desvelar as bases teóricas que alicerçam a construção da teoria dos sistemas, localizando-a no plano das matrizes jurídicas contemporâneas.

\section{Observações preliminares de ordem histórica, biográfica e bibliográfica}

Niklas Luhmann nasceu em Lünenburg, na Alemanha, em 08 de dezembro de 1927, estudou Direito na Universidade de Freiburg, entre os anos de 1946 e 1949. No início de sua vida profissional trabalhou como funcionário da administração pública alemã, sendo que, nos primórdios dos anos 60, encaminhou-se para a Universidade de Harvard para estudar administração e sociologia, tornando-se aluno de Talcott Parsons, momento em que tomou contato com o funcionalismo. Tal base teórica influenciou sobremaneira a primeira fase de suas reflexões sociológicas e o entendimento do direito como sistema funcionalmente diferenciado - pilar de sua posterior concepção de sistema jurídico auto-organizado e autopoéitico.

Relevante frisar, de imediato, que Luhmann teve como uma de suas principais influências o estruturalfuncionalismo de Parsons. Todavia, é num diálogo crítico-superador que vai ocorrer encontro entre os dois 
autores. A partir de uma releitura particular, vai dinamizar-se a construção que pode ser denominada de funcionalestruturalista, dando origem a uma original teoria social, que privilegia a função do sistema em detrimento de sua estrutura. $^{3}$

No retorno a Alemanha, Luhmann tornou-se pesquisador do Instituto de Investigações da Escola de Altos Estudos de Administração de Speyer, doutorando-se em 1966, na Universidade de Münster. Entre os anos de 1968 e 1969, ele ocupou a cadeira de Theodor Adorno na Universidade de Frankfurt. Posteriormente, ainda no ano de 1969, ingressou como primeiro professor contratado da Universidade de Bielefeld, onde realizou suas atividades intelectuais e acadêmicas até o ano de 1993, ocasião em que se licenciou após ser sagrado Professor Emérito de sociologia daquela instituição. Niklas Luhmann faleceu no dia 06 de novembro de 1998, em razão de uma doença que já havia comprometido suas atividades.

Em sua trajetória produziu um arsenal bibliográfico que supera setenta obras ${ }^{4}$, as quais se encaixam num programa de trabalho proposto no seu ingresso na Universidade de Bielefeld, que envolveu a tentativa de construção de uma teoria ou "super teoria", de explicação da sociedade e de todos os seus fenômenos: sua "teoria da sociedade". Nesse sentido, importante resgatar a descrição de Luhmann na introdução à sua obra publicada em 1997 "Die Gesellschaft der Gesellschaft' (A Sociedade da Sociedade), em que o autor revela que, em resposta a uma demanda da Universidade alemã acerca do alcance de seu projeto de investigação na instituição, oferece a seguinte manifestação: tema: elaboração de uma teoria da sociedade; duração: trinta anos; custos: nenhum. (CLAM, 2005b, p. 151)

Nessa ocasião, num primeiro momento, Luhmann tinha pensado que seu projeto poderia materializar-se em uma obra dividida em três partes: a primeira traria o marco conceitual para a compreensão da sociedade, ou seja, um capítulo sobre a teoria dos sistemas; a segunda apresentaria sua análise da sociedade, e; a terceira traria o exame dos principais subsistemas funcionais da sociedade. Os anos transcorreram e seu projeto original deu origem a uma vasta produção bibliográfica. Sem afastamento do objetivo maior, as partes do livro tornaram-se múltiplos livros de extensão e profundidade consideráveis. (RODRIGUEZ, 2002, p 24)

A primeira parte do projeto, relacionada com a elaboração de uma teoria geral dos sistemas sociais, materializou-se na obra denominada "Sistemas Sociais", a qual tem posição de centralidade, trazendo os pilares de sua proposta teórico-sociológica:

En él, se ofrece una madura teoría de lo social, entendido en términos sistémicos. Esta obra, por si sola, constituye un aporte clave a la discusión científica de fines del siglo veinte.

\footnotetext{
${ }^{3}$ Para maiores aprofundamentos ver: SCHWARTZ, Germano. A fase Pré-Autopoiética do Sistema Luhmanniano. In: ROCHA, Leonel Severo. SCHWARTZ, Germano. CLAM, Jean. Introdução a teoria do sistema autopoiético do direito. Porto Alegre: Livraria do Advogado, 2005a. p. 62 e seguintes. LUHMANN. Niklas. Introdução à Teoria dos Sistemas. Petrópolis: Vozes, 2010. pp. 35-59

${ }^{4}$ Interessante catalogação das obras de Luhmann encontra-se no anexo da obra: ARNAUD. André-Jean. LOPES Jr. Dalmir. Niklas Luhmann: do sistema social à sociologia jurídica. Rio de Janeiro: Lumen Juris, 2004. ps. 371-389.
} 
Recogiendo conceptos provenientes de la biología, la lógica, la sociología, la teoría del derecho, etc., Niklas Luhmann elabora una teoría que debe ser capaz de dar cuenta de todo lo social, incluso de sí misma. De allí, que su autor debe preocuparse de discutir cada elemento incluido en la armazón teórica, sin dejar nada de lado. (RODRIGUEZ, 2002, p 25)

A segunda parte envolve o tratamento do sistema da sociedade e encontra como bibliografia fundamental o texto "A sociedade da sociedade". Torna-se relevante salientar que a sistematização do debate sobre o sistema da sociedade perpassa inúmeras obras anteriores, em especial, o livro "Teoria da Sociedade", elaborado conjuntamente com Raffaele Di Giorgi. No entanto, é realçada a importância da obra "Sociedade da Sociedade" para a sociologia e para o direito. Tal aspecto é frisado por ROCHA, quando afirma que:

Luhmann condensa, de maneira magistral, todo o pensamento da teoria dos sistemas autopoiéticos no livro que se chama A Sociedade da Sociedade. Trata-se de uma obra extremamente importante e que ainda será considerada, na sociologia do XX, tão necessária como a de Max Weber ou Talcott Parsons e, principalmente, no caso do Direito, pois grandes autores contemporâneos, como Habermas, Derrida ou Foucault, não são juristas, enquanto Luhmann trata, com destaque, do Direito, do qual partiu a sua formação. Trata-se de uma vantagem para os profissionais da área jurídica essa afinidade e essa identidade real de Luhmann para com os juristas. (2009, p.18)

No que atine a terceira parte de seu trabalho, deu origem a diversos livros dedicados a explicação da operatividade dos diferentes subsistemas funcionais da sociedade, tendo como exemplo a religião, o direito, a política, a economia, a família, a arte, a educação, a ciência etc.; tornaram-se presentes discussões especialmente nas monografias escritas a partir dos anos de 1980, tais como: "A Economia da Sociedade", "O Direito da Sociedade", "A Arte da Sociedade" e "A Religião da Sociedade".

As obras mencionadas confirmam o caráter abrangente da teoria luhmanniana e sua busca de construção de uma observação de diferentes ângulos da sociedade e seus subsistemas, permitindo, ainda, observar o cuidado e a perspicácia de Luhmann no que tange as suas construções teóricas, inclusive no momento da titulação das obras, em que, conscientemente, desde o princípio, faz uso da proposição "da", em lugar da conjunção "e" (Direito da Sociedade, Religião da Sociedade, etc.), o que tem por objetivo deixar demarcado que sempre se trata da mesma sociedade e que as dimensões ou subsistemas da sociedade, não são algo que pode ser separado dela, elemento que destaca o caráter unitário da teoria. (RODRIGUEZ, 2002, p 26)

As observações acima expostas autorizam constatar a marca da interdisciplinaridade da construção de Luhmann, qualidade sempre destacada por aqueles que se debruçam sobre sua obra. Pode-se asseverar também, nesse aspecto, que Luhmann, em sua leitura sistêmica, avança no sentido de superação do paradigma funcional de Parsons, fundando uma nova metodologia, em especial no diálogo que realiza com a filosofia, a teoria do conhecimento, a biologia e a cibernética que permitem o aprimoramento do conceito de autopoiese, como se 
verá adiante. ${ }^{5}$

\section{A matriz pragmático-sistêmica e sua localização no plano da “Teoria do Direito”}

Ao buscar localizar a construção de Luhmann no plano da epistemologia jurídica, ROCHA (1999, p. 142) aponta que as principais teorias jurídicas contemporâneas podem ser reunidas levando em consideração o "campo de racionalidade" na qual estão inseridas, ou seja, podem ser agrupadas a partir da "matriz epistemológica" que impera na construção do conhecimento jurídico. Nessa perspectiva, assevera o autor que três são as grandes matrizes jurídicas, ou três são as etapas do pensamento jurídico: analítica, hermenêutica e pragmática (pragmático-sistêmica).

Relacionado com a matriz analítica ou normativismo analítico e suas reflexões lógico-formais sobre as normas jurídicas, pode-se dizer que:

[...] possui um vasto leque de aplicações. O projeto de construção de uma linguagem rigorosa para ciência foi adaptado para direito, principalmente por Hans Kelsen e por Norberto Bobbio. Estes autores podem ser considerados neopositivistas, pois postulam uma ciência do direito alicerçada em proposições normativas que descrevem sistematicamente o objeto do direito. Trata-se de uma metateoria do direito, que, ao contrário do positivismo legalista dominante na tradição jurídica (que confunde lei e direito), propõe uma ciência do direito como uma metalinguagem distinta de seu objeto. (ROCHA, 2013, p. 143)

Dessa forma, com o caráter, preponderantemente, descritivo e estrutural da matriz acima delineada, ficam claros os seus focos de atenção primordiais: (a) construção de uma teoria das normas jurídicas e (b) elaboração sistematizada de uma doutrina do sistema jurídico. Nesse sentido, verifica-se que tais elementos remetem diretamente às pretensões de Kelsen na "Teoria Pura do Direito" e de Bobbio com sua obra "Teoria do Ordenamento Jurídico".

Frente aos limites da matriz analítica, em especial sua incapacidade de pensar uma complexidade social mais ampla, assim como seu caráter descontextualizado, erige-se a matriz hermenêutica numa "tentativa de manter a estrutura normativa ampliando-se as suas fontes de produção de sentido" (ROCHA, 2005, p. 21). Como autores que podem ser catalogados no rol desse paradigma jurídico, destacam-se Habermas, Austin, Warat, Hart e Dworkin. Em síntese pode-se dizer que:

A hermenêutica é hoje uma derivação crítica da filosofia analítica, baseada nos trabalhos de Wittgenstein (Investigações Filosóficas) que redefiniu, em meados do século, a ênfase no rigor e na pureza da lingüística por abordagens que privilegiam os contextos e funções das imprecisões dos discursos. A hermenêutica, diferentemente, da pragmática, centrada nos procedimentos e práticas sociais, preocupa-se com a interpretação dos textos. (ROCHA, 2013, p. 145)

Com flagrantes avanços em relação à filosofia analítica, a hermenêutica apresenta uma possibilidade de

\footnotetext{
${ }^{5}$ Nesse sentido, conferir a análise de STICHWEH. The Present State of Sociological Systems Theory. In: SANTOS. José Manuel. O pensamento de Niklas Luhmann. Covilhã: Lusofia press. 2005. p. 347-371.
} 
reflexão sobre do direito que intenta resgatar a dimensão social do fenômeno, reconhecendo o caráter contextualizado da interpretação do material normativo. Desde as contribuições oferecidas pela filosofia da linguagem, a filosofia hermenêutica ressalta o aspecto produtivo e social do ato de interpretar os textos, superando o normativismo analítico e suas descrições. No entanto, não oferta uma leitura que permita a compreensão do social, elemento indispensável para o entendimento do direito em sua complexidade. Nesse âmbito, salienta-se que a "hermenêutica jurídica abre um importante ponto de preferência para a análise da sociedade, para a compreensão do Direito. Mas ela não explica suficientemente o que seja a sociedade". (ROCHA, 2005, p. 26)

No ambiente de crise das matrizes analítica e hermenêutica, no que se refere à capacidade de enfrentamento da complexidade sócio-jurídica, apresenta-se a matriz pragmático-sistêmica, cujo alicerce teórico principal está na obra de Niklas Luhmann, a qual promove uma:

[...] revisão da racionalidade jurídica, redefinindo seus critérios tradicionais de cientificidade, ao abrir-se para observações que enfrentam questões normalmente omitidas na atribuição de sentido do direito, como a consideração positiva da existência de paradoxos na relevância significativa. (ROCHA, 2005, p. 26)

Dito de outra maneira, avançando na questão relacionada com os paradoxos do sistema, verifica-se que a matriz analítica tende a ocultá-los, na busca de segurança e pureza. A matriz hermenêutica, apesar de constatá-los, não promove o enfrentamento, já a matriz sistêmica faz um uso criativo deles. (ROCHA, 1997, p. 19)

\section{Acercamentos iniciais da construção jurídica luhmanniana e seus antecedentes teóricos}

Os primeiros momentos das elaborações científicas do autor alemão, que marcam os alicerces da matriz sistêmica, estão relacionados com as leituras que faz da obra de Talcott Parsons, especialmente, da teoria funcional da sociedade, sendo seguido de um momento no qual serão inseridos elementos oriundos das ponderações do autor acerca do conceito de autopoiese.

Portanto, a teoria sistêmica do direito encontra duas fases associadas a evolução geral do pensamento de Niklas Luhmann:

1) a primeira, na qual Luhmann aperfeiçoa, após seus estudos em Harvard, o estrutural funcionalismo de Parsons. É nessa primeira fase que se colocam conceitos fundamentais para o desenvolvimento da fase posterior, 2) autopoiética (ou autopoietológica), que representa um avanço em relação a primeira, e que traz consigo as idéias biológicas de Maturana e Varella. (SCHWARTZ, 2005, p. 51)

É de se ressaltar que a arquitetura conceitual de Luhmann, em que pese a possibilidade de indicar ou delimitar um primeiro momento estrutural funcionalista e um segundo associado ao conceito de autopoiese, não pode ser objeto de uma visão compartimentalizada e estanque. Os elementos que se inserem e se articulam com conceito de sistema autopoiético - fase final do pensamento sistêmico - são encontrados desde o princípio de seus escritos e vêm sendo aprimorados e organizados no transcorrer de sua vida e obra. 
Sobre esse aspecto pondera CLAM que:

É difícil de "temporalizar" ou "historiar" com certa exatidão a evolução teórica de Luhmann por uma razão essencial, que reside no próprio estilo de produção científica luhmanniana. Em verdade esse produto corresponde a uma teorização que atravessa quotidianamente a linha da própria escritura, ordenando sob as diferentes rubricas do célebre fichário de Luhmann (...) A teorização luhmanniana encontra-se, dessa forma, continuamente em movimento. (2005b, p. 92)

No entanto, apesar dessa importante ressalva, optou-se pela manutenção de uma análise que respeita a sequencialidade apresentada tradicionalmente por aqueles que abordam o pensamento do autor alemão (duas fases de desenvolvimento), admitindo, inclusive, que tal organização se faz possível numa abordagem específica acerca do direito e do sistema jurídico.

Nessa orientação, as reflexões luhmannianas sobre o direito envolvem dois pontos diferenciados, embora conectados umbilicalmente, um primeiro voltado à análise da positividade jurídica moderna e suas características e, um segundo, em que se desenvolve, de maneira mais direta e clara, o conceito de sistema jurídico a partir da categoria da autopoiesis.

Aliás, sobre isso refere GUIBENTIF (2005, p. 206), que na primeira etapa do pensamento de Luhmann "o direito necessário para a sociedade moderna é expressamente qualificado de estrutura social, e não de sistema", ao que acrescenta que sua "arquitectura teórica será revista em profundidade nos anos seguintes, com a qualificação do direito como sistema social". Assim, com a revisão da compreensão da sociedade e sua percepção como sistema social, composto de comunicações, vão operar-se transformações contundentes na matriz jurídica sistêmica, que passa a observar o Direito sob o ângulo da autonomia e auto-referência (sistêmicos).

\section{A PRIMEIRA SOCIOLOGIA JURÍDICA DE LUHMANN: A POSITIVIDADE DO DIREITO E SUA DIFERENCIAÇÃO FUNCIONAL}

É correto afirmar que no pensamento de Luhmann "toda a sua teoria geral da sociedade é marcada pelo facto de o direito ter sido um dos seus principais objectos ao qual foi aplicada" (GUIBENTIF, 2005, p. 190). Em todas suas fases existe uma reflexão importante sobre o fenômeno jurídico, que evolui acompanhando um amadurecimento teórico sociológico do autor, demonstrando sua percepção, na mesma linha daqueles com quem dialogou no início de sua obra (Weber, Durkheim, Maine, Marx e Parsons), de que o direito na sociedade moderna é dimensão estrutural.

Ao levar em consideração tal observação, pretende-se neste item, sistematizar as principais ideias presentes na primeira fase do pensamento luhmanniano, que podemos chamar de pré-autopoiese e que abarcam, inicialmente, a conceituação de positividade, e, posteriormente, um avanço funcional-estruturalista, em que se pode asseverar que Luhmann estabelece bases sólidas para a revolução paradigmática que se dá a partir do 
conceito de autopoiesis do sistema social e jurídico.

Quanto à noção de direito positivo, Luhmann propõe entendê-la como o elemento específico da sociedade moderna, representando fator que a distingue das culturas anteriores.

Tal distinção é evidenciada por ROCHA:

$\mathrm{Na}$ sociedade moderna diferenciada não se pode pensar mais em critérios de verdade necessária e impossível, mas somente possível. A forma de sociedade moderna tem de enfrentar assim a complexidade produzida pela possibilidade de se tomar decisões sempre diferentes. Nesta linha de idéias, na modernidade não é mais possível se manter a concepção medieval dominante de Direito, o Direito natural: direito eterno, imutável, indiferente às transformações sociais. O Direito moderno, ao contrário, para sobreviver a uma sociedade indeterminada, será um direito positivo. Um direito diferenciado e construído por decisões. (2005, p. 12)

Luhmann conceituou o direito positivo como aquele que é reconhecido como válido porque alterável, atribuindo, portanto, dois elementos importantes do conceito: a validade e alterabilidade. A noção de validade aqui não se confunde com a conceituação tradicional do paradigma analítico, encontrado nas construções positivistas ou neopositivistas, apresentando um traço eminentemente sociológico. Aliás, sobre isso, pode-se referir:

[...] o conceito da positividade do direito é usual na filosofia e na ciência jurídica. Nesse âmbito ela designa, em termos genéricos, o caráter estatuído do direito. Em termos mais estritos, porém a questão do caráter estatuído do direito possui significados secundários, dos quais devemos nos desfazer para chegarmos a um conceito propriamente sociológico de positividade. (LUHMANN, 1983, p. 07)

Nessa perspectiva, é relevante apontar que o conceito de validade na obra de autor alemão é construído desde a noção de expectativas normativas. Partindo de uma concepção interacionista, sustenta que nas relações sociais existe um processo que pressupõe, por parte dos envolvidos, imagens antecipadas do que vai acontecer: as expectativas. (GUIBENTIF, 2005, p. 197). A não confirmação fática das expectativas e a reação frente à frustração, permite classificá-las em cognitivas ou normativas. Desse modo,

Quem tinha uma determinada expectativa, verificando que os factos não the corresponderam, pode ter duas reacções: pode mantê-la (se se reencontrar numa situação semelhante, voltar a esperar da parte dos outros o que esperou desta vez, embora tenha agora feito uma experiência decepcionante); ou pode abandoná-la (se se reencontrar numa situação semelhante, não voltara abordá-la com a mesma antecipação). Expectativas que estaríamos dispostos a rever em função das nossas experiências são chamadas cognitivas; expectativas que queremos manter são chamadas normativas. (GUIBENTIF, 2005, ps. 197198).

Em síntese, pode-se dizer que as expectativas cognitivas são aquelas que, presente o desapontamento, é possível adaptar-se a realidade, havendo propensão a assimilação (não são censuradas e desapontadas) e, expectativas normativas, são as que, existindo dano, não são abandonadas e são estabilizadas em termos contra fáticos (em caso de violação surge norma a posteriori, a norma jurídica). (SCHWARTZ, 2005, p. 78)

Tal raciocínio parte de dois pressupostos, primeiramente, que existem expectativas conscientemente diferenciadas, as quais apresentam um detalhamento suficientemente e uma estabilidade nos seus elementos, 
viabilizando um comparativo entre o esperado e o que se experimentou, em segundo lugar, que, tratando-se de expectativas conscientemente diferenciadas, sabe-se a priori qual será a nossa reação em caso de não correspondência entre essas e a realidade. (GUIBENTIF, 2005, ps. 197-198)

Nessa perspectiva, para Luhmann "dir-se-á, numa primeira abordagem, que uma regra é válida quando corresponde, na perspectiva de quem a conhece, a uma expectativa normativa" (GUIBENTIF, 2005, p. 201). Todavia, é necessário acrescentar para a compreensão da validade uma dimensão social. Nesse sentido,

Dizer que uma regra é válida implica não só que uma pessoa deriva desta regra uma expectativa de que não pretende abdicar, mas também que esta pessoa espera que outras pessoas derivarão uma mesma expectativa e que estão também dispostas a mantê-la. Ou seja: a pessoa que fala em validade de uma regra espera normativamente que esta regra corresponda, para as outras pessoas, a uma expectativa normativa. Afirmar que uma regra vale é afirmar que os outros devem considerá-la como uma regra obrigatória. (GUIBENTIF, 2005, ps. 202).

Nesse contexto, revela-se a importância atribuída por Luhmann para o direito no mundo designado da complexidade (excesso de possibilidades) e da contingência (desapontamento e risco), na medida em que assume a missão de controlá-las. É relevante sublinhar que:

[...] em se tratando de relações sociais, não temos uma contingência simples (estado das coisas já ordenado - por exemplo, a noite segue o dia), mas sim uma dupla contingência (expectativas sobre expectativas), isto é, a seletividade das possibilidades não depende somente de mim, mas também dos outros, do mundo que coloque estas possibilidades à minha disposição. Assim, o risco de frustrações aumenta e a estrutura do Direito (formada por expectativas) deve, com sua funcionalidade específica de reduzir a complexidade apresentada pela sociedade (ambiente do sistema do direito), caracterizar-se como uma generalização congruente de expectativas normativas. Isto repercute na possibilidade de uma dupla seletividade, necessária em um mundo sensorialmente constituído altamente complexo e contingente, conforme ocorre na estrutura do sistema jurídico, aliviando a excessividade de possibilidades. (CARVALHO, 2011)

No que se refere à característica da alterabilidade do direito positivo moderno, é lícito afirmar que ele se diferencia:

[...] pelo facto de se poder alterar os seus conteúdos e as expectativas que neles se apóiam. Isto é, a pessoa que, num determinado momento, retira de uma regra jurídica uma expectativa normativa, sabendo que os outros poderão ter a mesma expectativa normativa, também sabe, desde já, que a regra poderá, no futuro, ser alterada e que isto levará todos, ela incluída, a alterar as suas expectativas normativas. Ou ainda, visto numa perspectiva objectiva, pode, em qualquer momento, alterar-se uma regra de tal maneira que, efectivamente, as expectativas normativas da população acompanhem esta alteração. Noutras palavras, o direito positivizado permite produzir novas expectativas normativas e alterar as que em certo momento vigoram. (GUIBENTIF, 2005, p. 203)

Frente a tal contexto, pode-se perceber que as relações entre direito e sociedade na primeira fase da teoria de Luhmann apresentam alto nível de complexidade e, na modernidade da positividade jurídica, ambos se revelam condições de possibilidade recíproca. A discussão sobre essas relações é construída a partir da noção de que a sociedade moderna se caracteriza pela sua diferenciação funcional, isto é, na sociedade existem vários âmbitos de atividade que se diferenciaram cada um com características específicas, com função própria que se 
revelam necessárias para a reprodução do todo social. (GUIBENTIF, 2005, p. 204)

Nesse aspecto, GUIBENTIF (2005, p. 205) refere que:

[...] com efeito, por um lado, a diferenciação dos vários sistemas tornou possível, no seio de cada um deles, novas alternativas de acção (exemplos: a diferenciação do dinheiro torna possível actividades econômicas mais diversificadas, do que nas economias tradicionais; a diferenciação do sistema político favorece a contraposição de projectos políticos em competição, etc.). (...) Por outro lado, dado que cada sistema evolui segundo a sua lógica própria, podem surgir dificuldades na conciliação entre os seus desenvolvimentos respectivos (Luhmann cita nomeadamente o exemplo de constataçóes científicas que colidem com objectivos políticos ou econômicos. Num tal contexto, e indispensável poder criar novas normas, para novas actividades, e face as novas possibilidades de incompatibilidade entre diversas actividades. Daí a necessidade do direito positivizado, isto é, sempre mutável.

Importante acrescentar, que diferenciação do sistema político possibilita a positivação do direito, ou seja, "o sistema político moderno, com a sua capacidade de produzir decisões vinculativas, poderá assumir, entre as suas funções, a de produzir o direito positivo de que a sociedade, na sua globalidade, carece." (GUIBENTIF, 2005, p. 206). Torna-se fundamental frisar, ainda, que outros elementos, para além da diferenciação funcional, favorecem a positivação do direito, assegurada por "processos históricos" (causas possíveis) e por demais mecanismos que continuam a atuando. (GUIBENTIF, 2005, p. 206)

No que tange aos primeiros, pode-se destacar o papel que a jurisdição adquire como mantenedora da ordem, a recepção do direito romano e a separação e hierarquização entre direito natural e direito positivo, todos esses fatores que favoreceram o surgimento e aprimoramento do conceito de validade e contribuíram para a percepção de mutabilidade do direito. Quanto aos demais mecanismos acima mencionados, temos aqueles que asseguram a positividade do direito, de modo que neles estão envolvidas as ideias de legitimidade, uso da força, programa condicional e os que mantêm ou facilitam sua alterabilidade, quais sejam: virtualidades da programação condicional, distinção entre legislação e atividade dos tribunais e a sua reflexividade. ${ }^{6}$

\section{O SISTEMA DO DIREITO AUTOPOIÉTICO: OBSERVAÇÕES SOBRE FECHAMENTO OPERACIONAL E ABERTURA COGNITIVA DO DIREITO}

Nesse fragmento do texto, enfrentar-se-á de maneira mais detalhada a problemática da autopoiese do direito, apresentando as reflexões sobre o caráter operacionalmente fechado e cognitivamente aberto do sistema jurídico. Para tanto, pretende-se desenvolver uma descrição da sociedade como sistema autopoiético, com foco na compreensão das principais características atribuídas por Luhmann ao Direito.

\footnotetext{
${ }^{6}$ Para aprofundamento ver. LUHMANN, Niklas. Sociologia do Direito I e II. Rio de Janeiro: Tempo Brasileiro, 1985.
} 


\section{O Sistema Social, Sistemas Sociais e a autopoiesis}

A discussão sobre o surgimento e a manutenção da ordem social para Luhmann, envolve os conceitos de complexidade e dupla contingência. Mais precisamente, o conceito de redução de complexidade como definição ou autoafirmação de mundo frente um caos radical de possibilidades.

Nesse ínterim, a definição dos contornos de uma ordem social, assim como a possibilidade de sua manutenção, vincula-se a dissolução do caos a partir da seleção de uma possibilidade em detrimento das demais, afirmando um mundo como real. Tal processo de seleção permite a dissolução da desordem e possibilita a comunicação entre os indivíduos, criando expectativas compartilhadas, o que, no âmbito da complexidade não reduzida pela ausência de princípio de ordem, revela-se impossível. (GARCIA AMATO, 2004, p.301)

Portanto, o espaço onde são ausentes os limites e as orientações não são possíveis (dupla contingência em estado puro) é rompido por ato individual, que produz distinção e promove uma seleção, definindo uma possibilidade de atuação, oferecendo a outro indivíduo seguir ou não a seleção feita.

O sistema social emerge, assim, do encontro entre dois indivíduos (sistemas psíquicos) com capacidade de atuar contingentemente. Cada um deles vivencia sua própria contingência como disponibilidade sobre alternativas, enquanto a complexidade do atuar do outro é experimentada como complexidade. Ego reconhece em outro um alter ego: um sistema que, como ele, dispõe de alternativas e que não pode determinar as seleções que o outro fará, considerando-o como parte da complexidade do seu entorno. Na dupla contingência, ambos devem considerar a perspectiva do outro. Ocorre aqui uma observação entre eles que se traduz na coordenação de seleções feitas por Ego e por Alter. Nessa coordenação, cada um dos interatuantes submete a disposição do outro sua contingência, com o que se gera a complexidade sobre a qual surge o sistema social. (RODRIGUEZ, 2002, p. 30)

Nesse parâmetro, pode-se dizer que ocorreu a produção de uma inaugural:

[...] estruturação do horizonte do possível, que o torna pela primeira vez acessível em um código binário: aceitar ou não aceitar a seleção. Todavia, qualquer que seja a resposta, esta há de operar, por sua vez, como seleção a partir da qual a outra poderá conectar com idêntico código. Algo terá surgido indubitavelmente: comunicação, order from noise. (GARCIA AMATO, 2004, p.303)

Verifica-se, assim, que a sociedade na concepção de Luhmann, tem a comunicação como elemento central e constitutivo. Nessa perspectiva, a sociedade é comunicação e é composta unicamente por comunicações, sem a comunicação a sociedade não existira na medida em que ela (a comunicação) possibilita a redução da complexidade e a superação da dupla contingência mediante a concretização de seleções comuns. No entanto, a comunicação deve ser entendida como propriedade do sistema social, percepção que ultrapassa a ideia estreita de que ela se exaure na dimensão individual da consciência.

Como afirma GARCIA AMATO: 
[...] a comunicação não se esgota na dimensão psicológica ou individual, pois aquela função da comunicação apenas é cumprida na medida em que a transmissão (Mitteilung, utterance) com pretensões de informação, que um indivíduo leva a cabo, seja seguida pela compreensão (Verstehen, understanding) por parte de, pelo menos um indivíduo." Importante referir, que a comunicação realizada pelo sistema social distingue a sociedade do meio, que é composto do substrato físico e químico, da vida orgânica e dos sistemas psíquicos dos indivíduos. (2004, p. 305)

Esse primeiro processo de constituição da sociedade, como sistema social global ou sistema total de comunicações, viabilizado a partir do ato de seleção que garante a criação de expectativas compartilhadas, alcança níveis de complexidade crescentes com aumento do número de indivíduos e multiplicação das comunicações e comportamentos possíveis - a sociedade moderna.

Na medida que a complexidade aumenta, ocorre um processo de especificação e de geração de novos sistemas sociais que são os ( sub)sistemas da sociedade que ganham autonomia e autenticidade, com processos comunicativos diferenciados.

Mais precisamente, o fator fundamental na constituição de um (sub)sistema social reside na sua função, e esta não é outra que a de demarcar um âmbito determinado da complexidade operante na sociedade, com vistas a sua redução. Já não será necessário que todos se ocupem do todo para tudo. Cada (sub)sistema permite um tratamento setorial e simplificado de parte da complexidade com a qual se ocupa. E os demais (sub)sistemas, a seu turno, poderiam prescindir no tratamento do mesma, e a perceberiam como reduzida. A gênese de sistemas não é nada mais nada menos que a especialização funcional para a redução da complexidade. Somente assim a sociedade poderá evoluir; somente assim a sociedade poderá fazer-se mais complexa. (GARCIA AMATO, 2004, p.307)

Tais (sub)sistemas sociais são parte da sociedade e têm ela como seu meio na medida em que esses são sistemas comunicativos. Seu elemento diferenciador ou especificador, que confere autonomia e identidade, está relacionado ao código com o qual ordena suas comunicações, e que permite dizer o que está fora e o que está dentro do sistema. Assim, temos o estabelecimento de limites em que os processos comunicativo-seletivos são diferentes do meio, com um código binário próprio e função diferente.

Importante ressaltar, que os limites dos sistemas são estabelecidos mediante o sentido, isto é, uma estratégia de seleção de elementos ou possibilidades, a partir de um meio mais complexo. O que define, portanto, se uma comunicação pertence ou não ao sistema é o sentido, que diferencia o sistema do entorno, estabelecendo a fronteira entre os territórios.

Os sistemas, a partir de sua operacionalidade interna e nos limites desta operacionalidade recursiva, resultam numa estrutura que torna possível a estabilização, bem como na criação de uma identidade, relacionada com a delimitação de terreno de comunicações como certa ordem, tornando previsíveis as comunicações que se sigam de cada comunicação do sistema”: estruturas de expectativas. (GARCIA AMATO, 2004, ps.312)

Assim, mediante operações recursivas, o próprio sistema organiza e (re)produz os elementos, as estruturas e o desenvolvimento do próprio sistema, ou seja, de maneira autorreferente, os sistemas produzem aquilo que os confere unidade. $\mathrm{O}$ encerramento operativo ou clausura operacional leva a auto-organização e a 
autopoiesis.

O sistema, portanto, depende de sua própria organização, de modo que suas estruturas somente podem ser modificas desde operações internas, o que leva aos dois conceitos fundamentais mencionados, que devem ser claramente separados, pois dizem respeito a aspectos diferenciados.

Nessa senda, pode-se mencionar, ainda que a:

Auto-organização e autopoiesis são dois conceitos que devem manter-se claramente separados. Cada um acentua aspectos específicos do encerramento da operação. Os dois têm com base um princípio teórico sustentado na diferença e um mesmo princípio de operação. Ou seja, sistema só pode dispor de suas próprias operações; ou, em outras palavras, dentro do sistema não existe outra coisa senão sua operação. Esta operação única consegue configurar dois acontecimentos fundamentais, dentro do sistema: autoorganização e autopoiesis. (LUHMANN, 2010, p.112)

Os sistemas (enclausurados em sua operação) são auto-organizados, pois constroem suas estruturas a partir de operações específicas e são autopoiéticos, de forma que, a partir daí, podem autoproduzir-se, além de suas estruturas. Nesse sentido, LUHMANN refere que:

A categorização da autopoiesis assume como ponto de partida a questão radical da autonomia, já que define o sistema a partir de seus próprios elementos. Autonomia significa que somente a partir da operação do sistema é possível determinar o que é relevante e, principalmente, o que é indiferente. Consequentemente, o sistema não está condicionado a responder a todo dado ou estímulo proveniente do meio ambiente. Os sistemas não podem importar nenhuma operação a partir do meio. (...) Um sistema autopoiético produz as operações necessárias para produzir mais operações, servindo-se da rede de suas próprias operações. (2010, p.112)

No entanto, a compreensão dos sistemas como autopoiéticos não pode levar a uma noção de isolamento. Os sistemas somente podem existir e manter-se em sua clausura, na medida em que esses estão inseridos em um meio e podem realizar contatos seletivos com ele. Relevante ressaltar que na:

[...] concepção de sistema/entorno não existe uma oposição, mas sim uma diferenciação recursiva. Nos sistemas autopoiéticos, qualquer alteração do entorno pode refletir no sistema e vice-versa, porém esse reflexo não se dá de maneira causal ou funcional devido à operacionalidade fechada do sistema. Como as duas faces de janus: uma não existe sem a outra e, no entanto, uma não se comunica diretamente com a outra, embora ambas pressuponham uma a existência da outra. (RODRIGUES, 2000, p.271)

Os códigos próprios de cada (sub) sistema criam uma sensibilidade que permite uma relação de abertura cognitiva com o meio. Tal possibilidade dá-se com os chamados acoplamentos estruturais. A abertura cognitiva é determinada pelo próprio sistema e limitada por ele.

No plano dos acoplamentos estruturais, há possibilidades armazenadas (ruídos) no meio, que podem ser transformadas pelo sistema; portanto, mediante acoplamento estrutural, o sistema desenvolve por um lado, um campo de indiferença e, por outro, faz com haja uma canalização de causalidade que produz efeitos que são aproveitados pelo sistema. (LUHMANN, 2010, p.133)

Importante ressaltar, que um sistema autopoiético faz uso da diferença como orientação para diferenciarse do próprio meio. $\mathrm{O}$ fechamento operacional somente é possível no meio e esse é o correlato necessário da 
operação. Nesse sentido, pode-se dizer que os sistemas observam os outros sistemas utilizando esquemas de distinção, porém, a unidade da diferença constitui-se no sistema observador e não no sistema observado. (RODRIGUEZ, 2002, p. 36)

Seguindo a leitura de GARCIA AMATO (2004, p. 322):

Cada sistema forma parte do meio dos outros sistemas. Isso quer dizer que sistema não percebe aos outros como sistemas, senão como aquela parte da complexidade social que não se reduz com o ajuste ao código e aos programas próprios. Não significa isto que não existam relações entre os sistemas. Já sabemos que a mudança dentro de um sistema produz uma ressonância nos outros, que através de seus códigos próprios a percebem como um aumento de complexidade de seu respectivo meio, frente ao qual reagem aumentando sua própria complexidade para poder seguir delimitando-se frente a esse meio modificado, com o que geram alterações em sim mesmos que modificam o meio dos outros e ressonam neles, e assim sucessivamente. Assim se explica a evolução social.

Relevante frisar, que os sistemas produzem a chamada observação de segundo grau: observação da observação. Nesta observação de segunda ordem é possível observar o esquema de distinção utilizado pelo observador, porém, o observador de segunda ordem não pode ver seu próprio esquema de distinção. Isso não significa que os sistemas não realizam a auto-observação, justamente o contrário "la auto observación es un momento operativo de la autopoiesis del sistema porque la reproducción de los elementos ha de basarse en esta diferencia sistema/entorno: lo perteneciente y lo no perteneciente." (RODRIGUEZ, 2002, p. 36).

Destaca-se, por fim, que nenhuma observação está em condições de compreender a plena realidade do sistema que ela realiza. Pode somente fazer algo no lugar disso: pode escolher soluções substitutivas, de forma que é o que ocorre mediante a eleição das distinções com as quais o sistema efetua auto-observações. Se for suficientemente complexo, pode passar da observação de suas operações para a observação de seu observar e, por último, a observação do sistema mesmo. Em todo caso, o sistema deve poder fundamentar a distinção sistemameio, ou seja, deve poder distinguir entre auto é hetero-referência: aquilo que sistema atribui a si mesmo e aquilo que o sistema atribui ao sistema observado. (LUHMANN, DE GIORGI, 1995, p.46).

\section{O Direito Autopoiético e as (im)precisões sobre o fechamento do sistema jurídico}

Como destacado anteriormente, a percepção da sociedade na perspectiva autopoiética impõe no que atine as construções luhmannianas acerca do direito uma revisão profunda. Dessa forma, os constructos iniciais sobre o direito, seus elementos e suas funções serão revistos, ou seja, a ideia de positividade do direito, esboçada antes, com a noção de "sistema jurídico" como (sub)sistema da sociedade, será alargada.

Conforme afirma CLAM, a teoria sociológica Luhmanniana até então:

[...] havia tentado compreender a quase totalidade dos fenômenos do Direito funcionalmente diferenciado a partir dos processos de positivação. A grande novidade da última sociologia luhmanniana é precisamente a tese de que a positividade é, a partir de então, insuficiente para explicar isso que o sistema jurídico é hoje, com ele realiza sua função 
e quais são as evoluções internas que ele conhece. Será preciso, então, ir além de uma análise da autonomização por diferenciação. (2005b, p. 113)

Nesse contexto, é relevante salientar que o direito - autopoiético - passa a ser entendido como um (sub)sistema social que tem uma comunicação própria que permite a diferenciação do sistema jurídico do seu meio/entorno. Desse modo, na medida em que se constitui como (sub)sistema da sociedade, demarca suas fronteiras a partir de sua diferenciação.

Por isso, vale relembra que:

[...] nos sistemas funcionalmente diferenciados e na sociedade em geral um sistema funcionalmente diferenciado é constituído pelo conjunto das comunicações que fazem intervir uma determinada distinção, distinção que (1) dinamiza a autopoiesis, na medida em que a invocação de um termo convida a responder pelo outro termo, (2) identifica o sistema, pois a distinção é diferente para cada sistema diferenciado, (3) existe, é reproduzida, é estabilizada no tempo, pelo facto de intervir nas comunicações que geram um determinado sistema. Entre estes códigos binários, recordar-se-ão em particular as oposições seguintes: ter/não ter (economia), verdadeiro/falso (ciência), conseguido/não conseguido (arte), e recht/ unrecht, de acordo com o direito/contrario ao direito (direito). (GUIBENTIF, 2005, p. 190)

As mudanças, no que tange a compreensão do direito positivo de Luhmann, surgem atreladas, principalmente, a duas chaves de leitura quais sejam: a referência sistêmica do direito e sua referência social.

No que atine a primeira, observa-se o caráter operativamente fechado do sistema jurídico que produz seus próprios elementos e seu entorno. Assim, num sentido operativo, o sistema é totalmente fechado e identifica o que pertence e o que não pertence a ele (o jurídico e o não jurídico), o que nos remete para as ideias de autoobservação e observação de segunda ordem, desenvolvidas anteriormente, e, para a ideia de recursividade, isto é, produção de suas próprias operações a partir da rede de suas próprias operações.

Ademais:

[...] el sistema debe presuponerse a si mismo, para poner en marcha mediante operaciones suyas su propia reproducción em el tiempo; o com otras palabras: el sistema produce operaciones propias anticipando y recurriendo a operaciones propias y, de esta manera, determina qué es lo que pertenece al sistema y qué al entorno. (LUHMANN, 2003, p. 2829)

Percebe-se, ainda, que o fechamento operativo do sistema do direito realiza-se unicamente no nível de segunda ordem, mediante um esquema que tão só pode ser operado nesse nível. Somente quando os constructos desta forma de observação apresentam-se numa lógica recursiva (de uns em relação aos outros), o sistema adquire sua unidade de fechamento autopoiético.

Nesse aspecto, importante referir que:

El código, - conforme con el derecho/no conforme con el derecho -, solamente puede ser manejado en el plano de la observación de segundo orden, es decir, en el nivel de la observación de los observadores. Esta observación es indiferente respecto al hecho de si los observadores de primer orden - actores o víctimas -, clasifican su relación con el mundo de acuerdo al derecho o en desacuerdo a él. Si se imaginan que a ellos les asiste la justicia o que son víctimas, el observador de segundo orden puede juzgar eso mismo de otra manera. Y si 
en absoluto han pensado una referencia al derecho, el observador de segundo orden puede aplicar para ellos los valores: conforme a derecho/no conforme a derecho. (LUHMANN, 2003, p. 50)

Em segundo lugar, no atinente a sua referência social, deve-se aclarar que o sistema jurídico é da sociedade e somente pode ser compreendido na medida em que se entende toda a operação jurídica como uma operação social. Dessa forma, é (sub)sistema do sistema da sociedade sendo que a:

[...] sociedad no es, por lo tanto, solo el entorno del sistema jurídico. Ella es en parte más, - en la medida en que incluye las operaciones del sistema jurídico; y en parte menos, -en la medida en que el sistema del derecho tiene que ver también con el entorno de la sociedad: realidades físicas y mentales de los seres humanos; fenómenos físicos, químicos y biológicos que el sistema jurídico declare relevantes. (LUHMANN, 2003, p. 36)

Ainda, no que tange ao caráter fechado do sistema jurídico, é relevante acrescentar que a percepção de fechamento não pode ser confundida com isolamento, ou seja, com ausência de integração entre o sistema em seu meio/entorno/ambiente.

Dessa forma, o sistema jurídico é enclausurado operativamente, todavia, aberto no sentido cognitivo ou normativo. Com os acoplamentos estruturais, os sistemas realizam conexões com o meio/entorno/ambiente, procedendo a leitura a partir dos códigos internos e nos limites estabelecidos pelo próprio sistema, daqueles ruídos ou ressonâncias, que permitem transformações no interior dos sistemas.

No entanto, as modificações que se apresentam nas conexões sistema/meio e sistema/ambiente são aquelas que somente são possíveis na medida em que são previstas pelo próprio sistema, e se fazem nos termos da (re)leitura comunicacional.

Outro aspecto importante, diz respeito às ideias de legitimidade e validade do direito, que estão relacionadas, numa orientação autopoiética, a noção de fechamento e recursividade. Desde essa percepção, a validade não apresenta qualquer referência externa ao sistema: "La validez es un "valor especificamente propio" del sistema jurídico que surge de la realización recursiva de las operaciones propias del sistema y que no puede ser utilizado en ninguna otra parte. (LUHMANN, 2003, p. 69)

A validade, portanto, não é nenhuma condição a priori do conhecimento, não tem forma de uma afirmação cognitiva acerca do direito, bem como não é resultado de uma causa externa, relacionada com fatores transcendentais ou com a força organizada do Estado, mas somente a forma em que as operações fazem referência a sua participação no sistema, já que estão ligadas ao contexto de outras operações do mesmo sistema no momento que o reproduzem. A validade jurídica é a forma com que se participa da unidade do sistema. (LUHMANN, 2003, p. 69)

Outro ponto relevante da concepção sistêmica do direito é a hierarquização interna do sistema, com posição de centralidade reservada ao Poder Judiciário na relação com a legislação, resgatando as ideias de centro e periferia do sistema. Na teoria dos sistemas a legislação está localizada nas fronteiras do sistema, conectando-se 
com o ambiente/demais sistemas. A legislação, no entanto, ocuparia o papel de filtragem das irritações ambientais e os tribunais produziriam as operações jurídicas na lógica da recursividade.

\section{CONSIDERAÇÕES FINAIS}

A elaboração teórica de Niklas Luhmann pode ser considerada, no quadro da teoria sociológica contemporânea, como uma representante das "grandes teorias sociais" que buscaram descrever a sociedade em sua totalidade. A construção do sociólogo alemão, materializada em sua vasta bibliografia, demonstra com clareza sua obstinação pela interdisciplinaridade e suas pretensões de preparar um mapa cognitivo capaz de dar conta da compreensão da sociedade e de todos os seus fenômenos.

No caminho trilhado em busca do desenvolvimento de sua "super teoria", Luhmann dialoga com autores clássicos da sociologia (Weber, Marx, Maine, Durkheim e Parsons, etc), da biologia (Maturana e Varela), da cibernética (Bertelanffy), entre outros, da filosofia, teoria do conhecimento, o que faz de seu constructo uma rede complexa de conceitos, que representa uma revolução paradigmática no pensamento sociológico.

Edificado a partir de uma leitura crítica da teoria do conhecimento, o construtivismo radical de Luhmann proporciona o desenvolvimento de uma percepção que desmascara os limites do próprio conhecimento, quando questiona acerca do seu processo de produção policontextual. Em Luhmann, tudo pode ser explicado de múltiplas formas dentro dos padrões comunicacionais dos sistemas auto-referentes.

Seu pensamento sociológico traz em sua base o abandono da tradicional explicação das sociedades centrada na teoria da ação, arquitetando-se sob o conceito da sociedade como "sistema de comunicação", que surge vinculado a um processo de diferenciação funcional, como forma de superação da complexidade e da dupla contingência.

A sociedade e seus (sub)sistemas não são compostos de indivíduos, mas sim de comunicações, o que, deve-se ressaltar, não representa uma concepção do ser humano como algo de menor importância para o sistema social. Apesar de os indivíduos não comporem o sistema social, apresentam-se como meio/entorno/ambiente. De todo modo, o ser humano, sistema psíquico, encontra-se no centro de sua teoria, na medida em que a comunicação somente é possível a partir da linguagem e do encontro entre indivíduos.

Grande parte dos autores que estudam a teoria luhmanniana organiza suas reflexões separando dois momentos fundamentais, os quais encontram como linha divisória a introdução do conceito de autopoiesis em sua obra. Dessa forma, sustenta que o encontro de Luhmann com as compreensões teóricas da auto-organização, em especial, da biologia dos chilenos Maturana e Varella, promove um ponto de inflexão na sociologia do autor.

Tal cisão exige uma releitura de toda sua elaboração científica anterior, apresentando como conceito chave da teoria da sociedade a autopoiese. Importante reprisar que a compartimentalização do constructo 
sistêmico do autor alemão não pode ser entendida de forma rígida e numa concepção linear. A teorização de Luhmann encontra-se em movimento constante. Elementos que dão alicerce a compreensão da sociedade como sistema autopoiético estão presentes na sua primeira sociologia e crescem numa lógica interdisciplinar e circular em função da abertura e encontro de com os mais variados saberes.

No que atine ao próprio paradigma da autopoiese, é possível afirmar que foi elaborado de maneira cíclica e progressivamente com a recepção de alguns sistemas de ideias. As teorias lógicas (Gottard Günter e Spencer Brown) permitem superar as racionalidades científicas tradicionais, revalorizando a noção de paradoxo e viabilizando percepção auto-referencial dos sistemas - fechamento operacional, de modo que as teorias cibernéticas (Heinz Von Foester) trazem à tona o debate sobre a observação de segunda ordem: observação da observação. E, finalmente, as teorias biológicas (Maturana e Varella) que acrescentam a noção de que os sistemas podem produzir-se e reproduzir-se desde seus próprios elementos.

Quanto à problemática jurídica, relevante mencionar que essa sempre esteve no centro das atenções de Luhmann. Em todos os momentos de sua obra, encontramos o enfrentamento do debate acerca do fenômeno jurídico, podendo ser considerado um objeto privilegiado de análise em sua sociologia, o que nos permite afirmar que a partir de suas concepções nasce e desenvolve-se uma nova matriz sócio-jurídica: matriz pragmáticosistêmica.

Tal matriz é elaborada, também, em dois momentos distintos: antes e depois da introdução do conceito de autopoiese. Num primeiro momento, Luhmann traz uma investigação sobre a positividade do direito e suas características: validade e alterabilidade.

Neste ciclo de seu pensamento, presente de maneira acabada em sua obra Sociologia do Direito, é inserido o conceito de diferenciação funcional delineado em contornos estruturais-funcionalistas (encontro com Parsons), no qual o direito é entendido como estrutura da sociedade ou como um (sub)sistema funcionalmente diferenciado, que segue um código binário próprio: Direito/Não direito.

Segundo o autor, nas sociedades modernas marcadas pela alta complexidade e pelas contingências não simplificadas realiza-se um processo de diferenciação funcional em (sub)sistemas. A partir de um processo de especialização, surgem diferentes estruturas que visam superar tal cenário. Assim, os sistemas funcionalmente diferenciados são caracterizados, como se disse, por um código binário próprio que, mediante um processo original de leitura das informações, permite perceber quais as operações do sistema e quais não são.

Mediante a interação entre o valor positivo e um negativo, o sistema alcança a unidade. $\mathrm{O}$ código Direito/Não Direito permite identificar o que é jurídico, o código Governo/Oposição identifica o político, o Pagamento/Não pagamento revela a funcionalidade do sistema econômico etc.

Cumpre referir que a ideia de sistemas funcionalmente diferenciados pode ser interpretada como a 
grande contribuição do primeiro Luhmann à teoria do direito e traduz-se em elemento indispensável para a compreensão do sistema jurídico como sistema autopoiético. Todavia, são os estudos de Luhmann sobre o Direito, posteriores a "Sociologia do Direito", que trazem uma reflexão mais sólida sobre a "unidade do direito" e promovem o acabamento do conceito de sistema jurídico.

A segunda sociologia jurídica de Luhmann comporta uma visão da sociedade como um sistema social composto por comunicações. A sociedade é comunicação e somente existe comunicação na sociedade. Os sistemas sociais, nessa perspectiva, organizam-se mediante a comunicação. De imediato, importante frisar, que o conceito de comunicação não se enquadra na percepção tradicional que envolve a estreita compreensão do sujeito emissor que realiza a entrega a um receptor, mas, sim, ressalta um processo comunicativo que envolve três elementos: a informação, a participação e a compreensão.

A sociedade, segundo Luhmann, surge como sistema global de comunicações na redução da complexidade e ruptura com a dupla contingência em estado puro, garantido por um ato de seleção que promove o surgimento de expectativas compartilhadas e, portanto, de comunicação e inter-relações. Tal processo é seguido, em face da multiplicidade de indivíduos e complexidade crescente, por um cenário de (sub)sistemas com comunicações próprias que ganham em autonomia. Para a redução da complexidade, realiza-se um processo de especialização funcional que permite verificar, a partir do código interno próprio, os limites do sistema: definir o que é sistema e o que é entorno/meio/ambiente.

Tais (sub)sistemas formam parte da sociedade e tem seus limites definidos pelo sentido que permite a seleção do que faz parte e do que não faz parte do sistema. Importante ressaltar também que, para Luhmann, o sistema é auto-organizado, ou seja, produz sua própria estrutura.

Dessarte, o sistema na sua operacionalidade recursiva, no âmbito do processo comunicacional próprio, elabora aquilo que the confere unidade e autenticidade. Mais ainda, o sistema é autopoiético, pois produz as operações necessárias para produzir as demais operações, servindo-se sempre de suas próprias operações.

Assim, a autopoiesis leva a compreensão do sistema como operacionalmente fechado, que não pode importar nenhuma operação do meio/entorno - reproduz-se sobre a base dos acontecimentos auto-produzidos.

O conceito de autopoiesis do sistema, no entanto, não pode ser compreendido como processo que se realiza no âmbito do isolamento e da auto-criação. A autonomia do sistema não pode ser confundida como falta de conexão com o entorno ou ausência total de "câmbios" entre sistema/entorno/meio/demais sistemas. Tal percepção falha, na medida em que omite a reflexão sobre um conceito chave da teoria autopoiética que é o de acoplamento estrutural.

Por acoplamento estrutural, entende-se a conexão entre o sistema e o meio, a qual permite falar da abertura cognitiva dos sistemas autopoiéticos, isto é, a possibilidade que traz o próprio sistema de irritabilidade 
pelo entorno/meio/ambiente. Nas zonas de fronteira entre os sistemas e o entorno (demais sistemas) dão-se espaços de irritação que promovem ressonâncias ou ruídos. Tal aspecto autoriza dizer que existe influência entre os sistemas, todavia, sempre que pensarmos em uma ressonância ou ruído, devemos entender que ocorrerá uma (re)leitura, como base no código comunicacional próprio e, a partir de então, poderão surgir modificações, transformações no âmbito de um sistema, as quais não afetam seu código estrutural.

A partir de tais pressupostos conceituais, elabora-se a compreensão do sistema jurídico na parte final da teoria Luhmanniana, com destaque na obra "O Direito da Sociedade". Nesse contexto, o direito passa a ser entendido como um (sub)sistema da sociedade de caráter autopoiético.

Superando o conceito que surge associado à autonomização por diferenciação funcional, Luhmann vai considerar o sistema do direito como englobando uma comunicação própria (alicerçada na diferença entre direito/não direito), produtora de limites com o entorno, que, na lógica da recursividade, vai auto-organizar e desenvolver a produção de operações jurídicas a partir das operações jurídicas.

Tal sistema formata-se como operacionalmente fechado, todavia, é cognitivamente aberto. Trata-se de um sistema social que se encontra acoplado estruturalmente como o meio/entorno/demais subsistemas e, com eles, comunica-se na medida em que ocorre o ruído e a ressonância. No entanto, tal conexão dá-se como uma (re)leitura por parte de um sistema jurídico, que observa o outro e, a partir daí, dinamiza-se internamente as repercussões.

Importante referir, por fim, que o fechamento operacional do sistema é condição para sua abertura cognitiva, formando uma equilibrada equação. São duas faces da mesma moeda e nada de ambíguo encontra-se nessa compreensão. Aliás, nesse sentido, refere Luhmann que "um sistema jurídico, no que concerne a reprodução do sistema, deve estar apto a aprender, e por isso é concomitantemente um sistema fechado e aberto. Não se trata de uma contradição lógica, pois nós definimos clausura como reprodução recursiva e não como negação de abertura. A clausura torna-se muito melhor formulada com um paradoxo: o sistema é aberto porque é fechado, ou ainda, é fechado porque é aberto [...]" (LUHMANN, 2004, ps. 63/64)

\section{THE LAW IN THEORY FROM NIKLAS LUHMANN: COMMENTS ABOUT THE AUTOPOETIC "SHUTDOWN" FROM JURIDICAL SYSTEM}

\section{Abstract}

This paper, the result of an interdisciplinary literature review, look after the Juridical System particulars, as assigned by Niklas Luhmann, in his systemic theorical construction. In this perspective, finds his "think over object" in the (in)comprehension about the autopoetic character in Law. Focusing in structural closure of perceptions and cognitive openness of social (sub)systems, seeks to show how connections are created and related 
(communications) between Law and other (sub)systems of Society. For this, this paper introduce a biographical and theoretical revisits, rescuing the elements that allow us to properly understand this epistemological net constituted by the german sociologist.

Keywords: Niklas Luhmann; Juridical System; Autopoiesis; Law; Systemic Theory; Epistemology.

\section{REFERÊNCIAS BIBLIOGRÁFICAS}

ARNAUD. André-Jean. LOPES Jr. Dalmir. Niklas Luhmann: do sistema social á sociologia jurídica. Rio de Janeiro: Lumen Juris, 2004.

CARVALHO. Delton Winter de. O direito como um sistema social autopoiético: auto-referência, circularidade e paradoxos da teoria e prática do direito. Disponível no endereço eletrônico http://simaocc.home.sapo.pt/ebiblioteca/pdf/ebc_delton.pdf. Acesso em 10 de agosto de 2016.

CLAM. Jean. A autopoiese no direito. In.: ROCHA, Leonel Severo. SCHWARTZ, Germano. CLAM, Jean. Introdução a teoria do sistema autopoiético do direito. Porto Alegre: Livraria do Advogado, 2005a. Conclusão. Niklas Luhmann (1927-1998). In.: ROCHA, Leonel Severo. SCHWARTZ, Germano. CLAM, Jean. Introdução a teoria do sistema autopoiético do direito. Porto Alegre: Livraria do Advogado, 2005b.

GARCIA AMATO, Juan Antonio Garcia. A Sociedade e o Direito na obra de Niklas Luhmann. In.: Niklas Luhmann: sistema social á sociologia jurídica. Rio de Janeiro: Lumen Juris, 2004.

GUIBENTIF, Pierre. O direito na obra de Niklas Luhmann Etapas de uma evolução teórica. In.: SANTOS. José Manuel. O pensamento de Niklas Luhmann. Covilhã: Lusofia press. 2005.

LUHMANN. Niklas. Sociologia do Direito I. Rio de Janeiro: Editora Tempo Brasileiro, 1985.

Sociologia do Direito II. Rio de Janeiro: Editora Tempo Brasileiro, 1985.

DE GEORGI. Raffaele. Teoría de la sociedad. México: Universidad de Guadalajara. 1995.

A restituição do décimo segundo camelo: do sentido de uma análise sociológica do direito. In.: ARNAUD. André-Jean. LOPES Jr. Dalmir. Niklas Luhmann: sistema social á sociologia jurídica. Rio de Janeiro: Lumen Juris, 2004.

Introdução à Teoria dos Sistemas. Petrópolis: Vozes, 2010.

EL Derecho de La Sociedad. In.: http://lkservicios.com/maestria-20131/descargas/517derecho_luhmann.pdf. Acesso em 10 de janeiro de 2016.

ROCHA. Leonel Severo. Paradoxos da auto-observação: percursos da teoria jurídica contemporânea. Curitiba: JM Editora, 1997.

Da epistemologia jurídica normativista ao construtivismo sistêmico. In.: ROCHA, Leonel Severo. SCHWARTZ, Germano. CLAM, Jean. Introdução a teoria do sistema autopoiético do direito. Porto Alegre: Livraria do Advogado, 2005.

Observações sobre a observação Luhmanniana. In.: ROCHA. Leonel Severo. KING. Michel. SCHWARTZ, Germano. A verdade sobre a autopoiese do direito. Porto Alegre: Livraria do Advogado, 2009.

Epistemologia do Direito: revisitando as três matrizes jurídicas. Revista de Estudos Constitucionais, Hermenêutica e Teoria do Direito (RECHTD) 5(2):141-149, julho-dezembro 2013. 
RODRIGUES Jr. Léo. Autopoiésis e o sistema social de Niklas Luhmann: a propósito de alguns conceitos. In.: Sociologias. ano 2, nº 3. Porto Alegre: UFRGS, 2000.

RODRIGUEZ M. Dario. Invitación a la sociología de Niklas Luhmann. In.: LUHMANN. Niklas. El Derecho de La Sociedad. México: Universidad Iberoamericana, 2002

SCHWARTZ, Germano. A fase Pré-Autopoiética do Sistema Luhmanniano. ROCHA, Leonel Severo. SCHWARTZ, Germano. CLAM, Jean. Introdução a teoria do sistema autopoiético do direito. Porto Alegre: Livraria do Advogado, 2005.

STICHWEH. The Present State of Sociological Systems Theory. In.: SANTOS. José Manuel. O pensamento de Niklas Luhmann. Covilhã: Lusofia press. 2005.

Trabalho enviado em 29 de setembro de 2016.

Aceito em 16 de abril de 2017. 